\title{
UNA BRUJA RECORRE EL MUNDO: DE ESCÁNDALO A PEDAGOGÍA FEMINISTA, LA BRECHA DE MERCEDES VALDIVIESO
}

\author{
Rubi Carreño Bolívar \\ Pontificia Universidad Católica de Chile \\ Santiago, Chile \\ rcarreb@uc.cl
}

RESUMEN / ABSTRACT

La brecha de Mercedes Valdivieso fue leída en los años sesenta como un "escándalo" y luego, en los ochenta, como "la primera novela feminista de Latinoamérica" (Guerra-Cunningam 45), es decir, como si fuera un momento fundacional de la narrativa de mujeres. ¿Cómo podemos leer La brecha en la actualidad? ¿Cómo dialoga con una historia de la narrativa escrita por mujeres en Chile? ¿De qué forma recoge, o no, temas de la agenda feminista actual? ¿En qué aspectos radica su valor literario y político? Estas son algunas de las preguntas que orientan la escritura de este artículo.

Palabras clave: Crítica feminista, teoría de los afectos, Mercedes Valdivieso.

\section{A WITCH MOVES AROUND THE WORLD: FROM SCANDAL TO FEMINIST PEDAGOGY, LA BRECHA BY MERCEDES VALDIVIESO}

La brecha by Mercedes Valdivieso was read in the 1960s as a "scandal" and then, in the 1980s, as "the first feminist novel in Latin America" (Guerra-Cunningham 45). Thus, as if it has always been a founding moment of the narrative of women. How can we read La brecha today? How does it dialogue with the history of women narrative in Chile? In what way does it collect or not topics on the current feminist agenda? Which are its literary and political values? These are the questions that guide the writing of this article.

KEYWORDS: Feminism literary Criticism, Affect Theory, Mercedes Valdivieso. 
Una bruja recorre la política y el feminismo de Chile en 2021. Es un espíritu inquieto al que le gusta pintarse los labios rojos. Tiene muchos cuerpos y varias voces. Algunas exclaman: “¡Irací, sí, otra no! ¡Se siente, se siente, Jadue, Presidente!", asociando, sin temor, un fantasma con una bruja, es decir, los programas feministas a los marxistas. ¿Y qué pasó con las faldas escocesas y los aritos de perlas del conservadurismo chileno? Tienen su lugar, qué duda cabe. No solo en las otras ministeriales, las vice algo del patriarcado, sino que en una misma que a veces imita, envidia o juzga en sus pantalones y hasta en su capucha bordada, porque ya ha recibido demasiados golpes. Aun así, este lugar de statu quo se desestabiliza por la presencia de esa bruja demasiado viva, demasiado joven, que grita: "¡Ahora que estamos juntas, ahora que sí nos ven, abajo el patriarcado, que va a caer, que va a caer, arriba el feminismo, que va a vencer, que va a vencer!", y que aplaude, mientras baila con otras libres por la Alameda, saludando con todo el cuerpo y la voz, a las reinas populares, desde las tías y las mamis de la primera línea hasta las machis del Chile constituyente. Y aunque dejó de hacer caso, o porque dejó de hacerlo, sin obediencia alguna, es elegida diputada, alcaldesa, y en un futuro cercano, quién sabe, una de ellas sea la primera presidenta feminista y comunista chilena.

Y, en este escenario, ¿cómo se lee una novela publicada sesenta años atrás? ¿Ha hecho, y hace todavía, algún aporte a los nuevos roles de género de las mujeres que afirman que "la revolución será feminista o no será"?

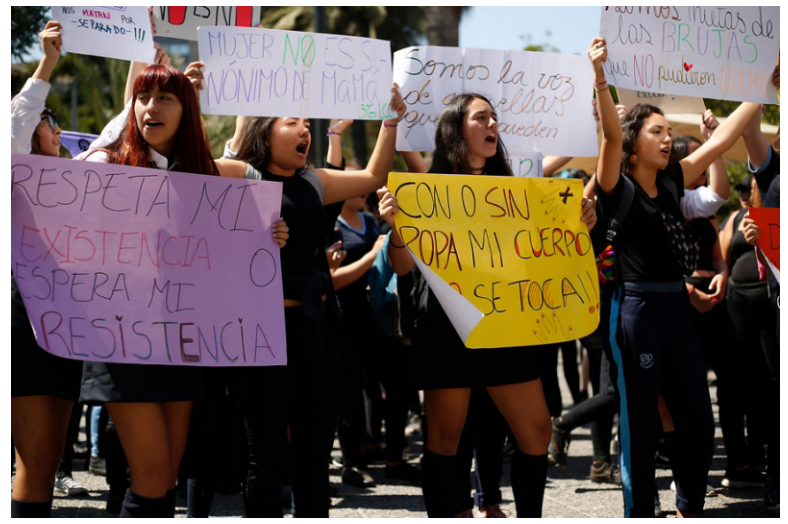

IMAGEN 1: "Los carteles que se robaron las miradas en la histórica marcha del \#8M en Chile"1.

1 Obtenido de Canal 13. Web. Publicado el 9 de marzo de 2019. Consultado el 15 de noviembre de 2021. Disponible en: https://www.t13.cl/noticia/nacional/ 
La protagonista sin nombre de La brecha (1961) tal vez podría haber sostenido uno o varios de los carteles de las recientes marchas feministas en Chile, toda vez que, aún hoy, lo que denuncia en esas páginas tiene vigencia. Sesenta años atrás, Mercedes Valdivieso puso en la agenda literaria temas como los derechos sexuales y reproductivos de las mujeres; cuestionó el rol materno como único e ineludible, señalando que, por lo tanto, se vuelve a veces maligno - tal y como aparece, posteriormente, en la narrativa de José Donoso y en la de Diamela Eltit y, como también observamos, en algunas escritoras recientes, en una suerte de reconsideración del tema-. Asimismo, establece una relación directa entre la familia patriarcal y la violencia sexual. Finalmente, explora la relación entre género, trabajo asalariado y artístico, que une a La Brecha con el marxismo del "primer Marx", el de los Manuscritos económico-filosóficos, y con el feminismo de la igualdad, es decir, el que busca una posición similar y equitativa en el campo de lo público para hombres y mujeres. Es quizás este punto el que vincula a La brecha con una tradición de escritoras, que va de Marta Brunet a Diamela Eltit, en la que el trabajo es visto como una soltura de la cadena que el patriarcado capitalista o neoliberal ha puesto también a las mujeres. Por ende, no habría redención o dignificación a través del trabajo asalariado, que se rige por los mismos "patrones" que el domestico: pagar nada o casi nada por el trabajo ajeno.

Y sin embargo, los años sesenta en Chile trajeron las luces de los primeros bikinis, barbas y minifaldas meneándose al compás de la Nueva Ola, que expandía sus ondas en una radio a pilas: "las olas al llegar, parecen murmurar, la canción que nunca calla" canta Cecilia con su corte de pelo y apariencia andrógina, a lo Rita Pavone, en una precuela de lo cuir. Al otro lado de la Cordillera, Sandro, "el Gitano", desata sus caderas, totalmente confiado en que hundirá las manos en aquel trigal y que es y será "el molino de tu amor", ay. De este modo, la cultura popular exhibe ciertas escandaleras consensuadas que van marcando, a buen ritmo, que los tiempos definitivamente estaban cambiando. Incluso en la política, la recién creada Democracia Cristiana desea un Chile con justicia social y reforma agraria para dejar atrás el oscurantismo de las inequidades: "Brilla el sol de nuestras juventudes, la noche muere en el ayer", como indica el himno democratacristiano. Pero, desafortunadamente, el peso de esa noche se hará sentir aún con más violencia en la medida que muchos y muchas coreen el "Se siente, se siente, Allende, presidente". Aun 
así, todavía se espera y se cree en que la primavera humana derrotará las formas clericales, conservadoras y vigilantes en las que se construyen los géneros sexuales y que generan una enorme exclusión para gran parte de la humanidad.

En cuanto a la academia, es el tiempo que prepara y produce la Reforma Universitaria, descrita por Isabel Torres del siguiente modo $^{2}$ :

Los hijos de las familias adineradas se rebelaron contra sus familias explotadoras. Los hijos de los obreros, se rebelaron contra la injusticia de que eran objeto, contra las inmensas dificultades de ser estudiante pobre; los de clase media, se rebelaron contra las aspiraciones y forma de vida de su clase; los académicos jóvenes contra los profesores más viejos que no fueron sensibles a sus aspiraciones académicas; los trabajadores no académicos, se rebelaron contra su condición subordinada, contra su trabajo a menudo aburrido y sin sentido. Así, la universidad entera se rebeló contra sí misma y contra el Estado, contra las limitaciones estructurales de la sociedad nacional y contra las fuerzas imperiales que imponían su dominio fuerzas imperiales que imponían su dominio político, cultural, económico y militar (147).

En lo literario, es el tiempo del boom narrativo y de José Donoso, que ha logrado salir del "horroroso Chile" escribiendo sobre él e internacionalizando su carrera. La novela chilena también vive un momento positivo, pues

2 A propósito de oscuridad, recientemente las universidades públicas chilenas han recibido un oficio proveniente de la Cámara de Diputadas y Diputados como respuesta a una solicitud de los Diputados Cristóbal Urruticoechea y Harry Jürgensen para que: "informe a esta Cámara sobre los cursos, centros, programas y planes de estudio que se refieran a temáticas relacionadas con estudios de género, ideología de género, perspectiva de género, diversidad sexual y feminismo" (Tapia párr. 3). Me pregunto si una vez que se identifique a los, las y les académicos ¿Qué harán? ¿Los enviaran a la colonia, como en El cuento de la criada, como "traidores del verdadero género"? Al ser entrevistado, Urruticoechea agregó que los académicos "mienten, (no hay) ni censura ni homofobia. Victimizarse es propio de esta ideología sectaria y totalitaria, ideología que pretende secuestrar el lenguaje, destruir todo a su paso (a través de su militancia callejera), quebrar todo tipo de costumbres y abitos (así en el original) para revelarse ante lo que llaman tradición hetero-capitalista, que no es otra cosa que la destrucción del vínculo padres/hijos, la destruccion de la relación heterosexual, la destrucción de la familia, su fin más codiciado" (Tapia párr. 11). Seguramente muchas quisiéramos darle las gracias por el crédito, pero, sin duda, esto lo ha hecho antes el mismo capitalismo patriarcal que ni siquiera ha querido legislar para reducir la extensísima jornada laboral de los chilenos y chilenas y que cree que las mujeres solo somos cuerpos que prestar. 
la generación del cincuenta está consolidada y en plena producción. La editorial Zig-Zag ofrece la posibilidad a los escritores y escritoras de ser promocionados y publicados y, tanto la crítica periodística como la académica, están convirtiendo estos textos dispersos en un corpus reconocible para un público amplio de lectores y lectoras. La narrativa escrita por mujeres recoge algunos de los temas de la llamada Generación de los 50, como la decadencia de la burguesía chilena, las llamadas "crisis existenciales" vistas a la luz del psicoanálisis y la desintegración del poder de las familias burguesas. Sin embargo, les incorpora una perspectiva de género que marca una diferencia en el corpus global de novelas. De este modo, las crisis tienen que ver, fundamentalmente, con el tránsito de la casa a la calle -ese pequeño paso para las mujeres y gran paso para la humanidad-y la sustitución o la ampliación de los roles de madre y esposa a trabajadora y profesional. De alguna forma, las escritoras de los sesenta quedan inscritas en la Generación del 50 con algunas especificidades propias de su experiencia como mujeres. Marta Brunet, que escribió María Nadie el año 1957 y Amasijo en 1962, ha quedado atrás, perdida en el neocriollismo, y quizás por eso no se la menciona, siquiera, como un antecedente de la novela feminista en Chile. En esa época y hasta avanzados los setenta, no hubo una mirada sostenida desde el género sobre la historia de la literatura chilena e incluso de mujeres a secas y muchas escritoras quedaron, según el decir de la poeta Elvira Hernández, "desclasificadas" (183) o mal ubicadas, porque carecen de un antecedente femenino o la reescritura solo se lee desde la supuesta copia que las precursoras que han logrado inspirar. Aquí no se trata de "biologizar" la escritura, pero sí de reconocer que lo femenino como categoría cultural ha establecido rupturas y también continuidades. El conocimiento de esta historia hace posible no reiterar temas, problemas y estrategias narrativas como si fueran nuevas y, por otro lado, impide quedarse sola hablándole a una gata en una plaza vacía, como si se fuera María Nadie, sin tradición, ni otras, ni una comunidad cultural. La "imaginación parricida" quizás haya sido una estrategia patriarcal, favorable para posicionar distintos tipos de vanguardia; la "matricida" en cambio, es, a mi juicio, una mala estrategia, pues la invisibilización o minusvaloración de la escritura de mujeres es demasiado grande como para ostentarse como "única", "primera", "la mejor" y borrar por propia mano a todas las demás.

Para Adriana Valdés, la marcha del proceso vital y narrativo que lleva a las mujeres de los sesenta al mundo de lo público establecería un cambio en el paradigma de la literatura femenina: 
La novela anterior era a menudo lenta, encaminada a una exploración poética de la vida interior, ambientada, generalmente, en el campo; la nueva tendrá una acción vertiginosa, reflejará un mundo urbano y mostrará personajes desorientados, escépticos, en conflicto con ese mundo (127).

Cabe señalar que, para la mayoría de las escritoras de los sesenta e incluso posteriores, María Luisa Bombal no fue un referente. Sufrió la paradoja de ser una de las pocas recordadas y citadas -aun cuando no se le dio el Premio Nacional de Literatura-, fundamentalmente, por hombres, y al mismo tiempo, de ser casi ignorada por las narradoras. El ser considerada una expresión de la naturaleza, justo en el momento en que las mujeres luchaban por tener un lugar en el mundo cultural, seguro no era lo más conveniente. Esta asociación con una idea poderosa y por ende, irrepresentable, como ha señalado Craig Owens (45), no impide que haya representaciones de las mujeres, pero sí favorece que sus autorrepresentaciones carezcan de validez. Así mismo, según Aura Cumes en "Mujeres indígenas, patriarcado y colonialismo: un desafío a la segregación comprensiva de las formas de dominio" (9), la naturaleza en el contexto patriarcal se asocia a lo conquistable, explotable y está sujeto, incluso, a tortura, como se observa, por ejemplo, en el cuento "La historia de María Griselda" (1946) de Bombal. Pareciera ser que ninguna de las escritoras de la generación posterior a Bombal quería que una trenza bombaliana la arrastrara de vuelta al fundo como en una película coreana de terror. Nadie iba a dejar su legítima aspiración de tener un lugar "en el campo" cultural, por un lugar en "el campo", espacio en el que ni siquiera las élficas protagonistas bombalianas parecían sentirse totalmente a gusto. De todos modos, y como leemos en la novela La mampara (1946) de Marta Brunet o en el cuento "Trenzas" (1940) de María Luisa Bombal, hay una escisión en la elección perversa que obliga a las mujeres a posicionarse como naturaleza o a ir en contra de ella ${ }^{3}$. El ecofeminismo ha intentado resolver esta separación a través de conceptos como "esencialismo estratégico", o al mostrar las relaciones entre patriarcado, colonialismo y neoliberalismo como una matriz de sujeción hacia las mujeres y a la naturaleza.

Tanto en La Mampara como en "Trenzas" se narrativiza la elección excluyente de dos hermanas, una que sale al mundo de lo público y otra que queda atrapada o elige quedarse en la casa asociada a la naturaleza y a los roles de género conservadores. 
De este modo, La brecha estrena un modo de representación que vincula a las mujeres con el trabajo y con la acción. Ya no serían parte de una la naturaleza entendida como pasiva y misteriosa, sino, por el contrario, se opondrían a esta identificándose con la cultura y con el orden simbólico. La cultura, por cierto, se asocia fundamentalmente a lo paterno y a lo masculino. El padre de la protagonista encarna el progreso, la audacia y la creatividad. Lo que viene de él se constituye en lo "deseado" por la protagonista. Él le hereda los libros, las aventuras, la libertad sexual y también la rebeldía. Si lo materno le propone una versión "demonizada" de la Virgen, es decir, la maternidad en sus aspectos controladores, su padre le ofrece una versión "angelizada" del demonio:

- ¿Ves esos cachos que quieren crecer bajo la piel?

Presionaba los huesos redondeados más arriba de las cejas, tocaba después los míos.

-Eres como yo un poco hijo del diablo; pero no hay que temerle, es positivo, todo el progreso se lo debemos a él (Valdivieso 27-28).

Las protagonistas bombalianas no tienen una madre, solo a Zoila, la trabajadora doméstica que es testigo de las violencias y de la infelicidad que experimentan. El padre y los maridos no solo son decepcionantes en tantos aspectos, sino que aparecen como una expresión apagada del capitalismo patriarcal: son los dueños de los fundos que encierran, o quieren poseer, todo asomo de creatividad y de placer que no pueden ofrecer.

Veinte años después de la publicación de "El árbol", de María Luisa Bombal, La brecha relata casi la misma historia que la presente en el cuento: desde su situación de "separada" una joven mujer burguesa rememora su infancia, su matrimonio y la ruptura matrimonial. No obstante, a diferencia de Brígida, la protagonista sin nombre de La brecha tiene amantes reales, logra un acuerdo legal para su separación, viaja y vive fuera de Chile, ingresa al mundo del trabajo y tiene un salario con el cual mantiene su hogar.

La brecha fue un verdadero éxito editorial, así lo demuestran sus cinco ediciones sucesivas y la gran efervescencia crítica a la cual estuvo expuesta. Al momento de ser publicada, fue leída como un "escándalo" que se nutría de la porosidad entre los géneros textuales. ¿Era una novela, una novela "en claves" o un testimonio que pretendía mostrar las experiencias "reales" de las mujeres de comienzos de los años sesenta en Chile? Por otro lado, ¿bastaba con romper los verosímiles sociales de su época para ser una "buena 
novela" o solo se trataba de un "texto de urgencia", "necesario"? En sus primeras ediciones, La brecha se entendió como una extensión de la vida de la autora, un libro de memorias, incluso un testimonio. En palabras de su primer prologuista, Fernando Alegría, se trataría de "un sencillo testimonio de vida intensa, apasionada, libre" (cit. en Valdivieso 10). Inducen a este tipo de lecturas los nexos entre la vida de Mercedes Valdivieso y la de la protagonista ${ }^{4}$, así como la mezcla de elementos ficcionales e históricos en el texto y el proyecto literario de Mercedes Valdivieso, descrito por ella misma como "denuncia" y "franqueza":

P- ¿Cuál le parece que es la misión más importante de un escritor en la actualidad?

R- Denunciar los males de nuestra realidad social que está en crisis, y abrir nuevos caminos.

P- ¿Cuál considera que ha sido el aporte de Mercedes Valdivieso en la literatura chilena?

R- La franqueza. Decir en voz alta lo que todos pensamos en voz baja, y nadie se atreve a expresar (“Autora de La brecha" 11).

El efecto de realidad del texto produjo reacciones encontradas, aunque predecibles, entre los críticos y quienes leían la novela. Mientras los primeros le declararon un "proceso a la morbosidad" ("Proceso" s/p), los otros y otras agotaban, con total felicidad, edición tras edición. Las primeras críticas no se centran ni remotamente en una valoración de orden literario. Por el contrario, "lo novelesco" quedaría eclipsado por su contenido de carácter testimonial y, por ende, el juicio pasa por si lo narrado es o no verificable, de modo que se pueda sostener el verosímil realista de la historia. De este modo, Raúl Silva Castro le critica a Mercedes Valdivieso y a Margarita Aguirre el que "mientan", solo para hacer más dramática la denuncia de sus textos. Quizás porque el

4 Las primeras novelas de la autora contienen numerosos rasgos autobiográficos. En La tierra que les di, aparece un personaje que estudia medicina después de enviudar al igual que la madre de Mercedes Valdivieso: "Mi recuerdo de infancia más persistente es el de mi madre, inclinada por las noches sobre sus libros, estudiando bajo una lámpara verde. Ella iba a la Escuela de Medicina con crespones de viuda" ("Autora de La brecha" 11). La abuela que aparece en el texto también tiene características de la abuela de la autora, pues ambas habrían poseído un fundo en el que la autora y protagonista pasaban la infancia. Este personaje de la abuela vuelve a aparecer en La brecha. 
lugar de enunciación de lo femenino ha sido, tradicionalmente, la debilidad y la falsedad, sobre todo cuando cuentan la historia desde su propio punto de vista, Silva Castro pierde el norte literario y les critica, precisamente, que son novelas, sino "invenciones". Su valoración literaria pasa porque obedezcan los verosímiles legales y sociales que detentan roles fijos para las mujeres, y no por ser capaces de realizar un mundo ficcional propio del género narrativo:

Yo no albergo la menor duda de que el talento que respectivamente anima a Margarita Aguirre y a Mercedes Valdivieso es de grande importancia, y acepto que su presencia en las letras chilenas contribuye a dar a éstas una nueva dimensión, perspectivas más amplias, todo lo lindo y halagüeño que se quiera suponer. Pero... en ambos casos, lo que se imagina o presupone tiene importancia en el desarrollo de los sucesos, y podemos imaginar entonces que no se trata de invenciones meramente gratuitas o simples descuidos si se quiere. No, las invenciones han sido fraguadas por las novelistas para dar dramatismo a la situación, hondura y gravedad al conflicto y, en fin, para cimentar condenaciones de orden social (Silva Castro 10).

Lo que hay detrás de estas palabras, me parece, es que las autoras no habrían sufrido tan radicalmente las violencias patriarcales mencionadas en las novelas y que el crítico omite y replica en su texto. Las autoras no son testigos fiables ni pueden hablar en su propia causa. Silva Castro cae en su propia trampa al leer ingenuamente las novelas como "verdaderas" y no como ficcionales, así como al reparar las inconsistencias legales - por ejemplo, decir que no existía entonces el divorcio (promulgado en Chile recién en 2004)-. Silva Castro releva que el "discurso mentiroso" de la literatura, usado desde el origen de los tiempos para decir lo que no se dice, no puede usarse por las mujeres de suyo "mentirosas" (ibid.).

Luego de un silencio crítico de casi veinte años, La brecha fue reeditada en inglés en Estados Unidos y estudiada en la academia norteamericana como una de las primeras novelas feministas de Latinoamérica. Sin duda, contribuyeron a este resurgimiento de La brecha los estudios del crítico chileno Marcelo Coddou y, fundamentalmente, de la escritora y crítica feminista Lucía Guerra Cunningham ${ }^{5}$. En este contexto se vuelve a reeditar,

En los años ochenta, junto con una nueva reedición de La brecha, Mercedes Valdivieso vuelve a Chile y publica Maldita yo entre todas las mujeres. La novela recoge la 
esta vez en Chile generando nuevas aportaciones críticas. En palabras de Marcelo Coddou:

En La brecha es posible distinguir, a lo menos, dos sistemas modelizadores a los que se opone y transgrede, uno delimitadamente literario - el canon establecido para una literatura definida por la tradición como "femenina", cuyas norma subvierte-, y otro no-literario: el de las normas aceptables como conducta para la mujer (37).

Desde esta perspectiva, el valor de La brecha radicaría solo en su ruptura respecto a la literatura femenina anterior -cuyo paradigma escogido es el de Bombal- y en la transgresión a las hegemonías discursivas que restringen la imagen consensual de las mujeres. Lucía Guerra Cunningham, enorme estudiosa de María Luisa Bombal y a quien debemos la inspiración de gran parte de las lecturas que hoy circulan en torno a ella, también valora el que el texto de Valdivieso haya sido escrito en un lenguaje claro, accesible y, en cierta medida, denotativo:

En la evaluación crítica de la narrativa chilena se salvan aquellas escritoras que adoptan la máscara de la virilidad o presentan conceptos inofensivos para el orden burgués y patriarcal... ¿Qué habría ocurrido a nivel de la recepción del texto si las protagonistas de María Luisa Bombal, hubieran elegido el verdadero adulterio, y no aquellos amantes lícitos envueltos en un girón de niebla, desplazados a un árbol que crece frente a la ventana, o metaforizados en un oscuro clavel y un techo de avellanas? (77) .

premisa estudiada por la corriente de crítica feminista “imágenes de la mujer", que postula que las mujeres somos leídas como vírgenes o brujas y dialoga también con la experiencia teórica chilena que entiende lo femenino como un asunto de poder en que el sujeto es víctima de una triple sujeción: la colonial-imperial, la del patriarcado y la correspondiente a vivir en un país en dictadura. En Maldita yo entre las mujeres, la "bruja" Catalina de los Ríos y Lisperguer vive en carne propia ser el chivo expiatorio social de la colonia. Por otro lado, revela su condición de mestiza y, como en otros textos del periodo, habla de los soldados españoles en diálogo manifiesto con los militares chilenos. Valdivieso aporta a este entramado teórico la recreación de un habla colonial barroca y también los saberes concebidos por la escritora como subalternos y efectivos: la cama, la comida, los saberes asociados a las brujas y los referidos a plantas y ensalmos. Tanto la novela como la presencia de Valdivieso en Chile, así como el retorno de críticas en el exilio como Soledad Bianchi y Raquel Olea, ponen otro horizonte en un campo de estudio emergente: la crítica feminista que encuentra un momento cúlmine en el congreso "Escribir en los bordes" del año 1987. 
Guerra Cunningham elige omitir que, entre la autocensura y la necesidad de expresión, existe una fuente inagotable de riqueza literaria, que es lo que Bombal, precisamente, productiviza en su escritura. A mi juicio, ambas escritoras enfrentan al orden patriarcal y burgués del que provienen y eligen distintas estrategias para poder desafiarlo. En ambas narrativas hay una elección consciente entre "el decir y no decir", según la expresión de Beatriz Sarlo; un juego entre lo novelado y lo no-velado, ya sea se use el estilo vanguardista, inaccesible para algunos, o bien el testimonial, pero rotulado como novela. Parafraseando a Lucía Guerra Cunningham, ¿qué hubiera pasado si, efectivamente, La brecha se hubiera publicado como testimonio y no como novela, es decir, si el nombre de la autora se hubiera superpuesto al de la protagonista? Quizás la autora habría sido excluida de algunos trabajos, cualquier juicio de custodia se hubiera dificultado, e, incluso, podría haber terminado presa al reconocer el delito de un aborto inducido. Aún hoy, existen cosas que en Chile solo se pueden decir bajo el discurso literario.

El texto de Valdivieso apuesta por ese caminar por el borde delgado entre ficción y realidad. Cuando creemos que se trata de un testimonio que le permite a su autora "denunciar los males de la sociedad que está en crisis" ("Autora de La brecha" 11) surge la novela que nos recuerda que lo dicho es solo literatura. De este modo, el que la protagonista no tenga nombre ayuda a equiparar la figura de la autora con la narradora, estrategia clave del género testimonial. Sin embargo, cuando los lectores asocian a la protagonista con la autora, Valdivieso se encarga de desmentirlo y señalar que lo narrado podría ser la historia de casi cualquier mujer:

P- ¿Le molesta que sus lectores identifiquen su vida privada con su novela?

R-Sí, ciertos lectores han resuelto identificar mi vida con La brecha, pese a mis negativas al respecto, hacer de carne y hueso un personaje que no tiene nombre. ¿Es que están defendiendo algún otro nombre y de qué...? (ibid.).

Quizás la divorciada que se hace un aborto y vive sola precisa de una "capucha" para poder expresar sus circunstancias. La invención "Mercedes Valdivieso" es también una estrategia defensiva. Convertida de Mercedes Valenzuela en Mercedes Valdivieso, escribe amparada en un estado civil, una clase social y una "marca literaria", la de su marido de entonces, el escritor Jaime Valdivieso: 
Mi marido cuando vio que el libro podía ser un escándalo, me dijo que debía llamarme Valdivieso para que sepan que estás casada. ¡Siempre lo masculino!" Aunque se contrapone con la temática del libro, hay épocas en la vida que hay que ser sabio. Yo no claudiqué del hecho de querer ser yo misma, bastaba con el libro. Y hoy, que quedé sola, sigo con Mercedes Valdivieso", dice riendo (cit. en Figueroa 6).

La brecha narra, bajo un formato realista, la vida privada de una mujer burguesa, su sexualidad y su modo de vivir las relaciones. Así, permite a una gruesa cantidad de lectores y lectoras fisgonear en un cuerpo que tradicionalmente había estado "custodiado", es decir, conformado a partir de estereotipos de género y oculto completamente en lo personal e íntimo. Sin embargo, no creo que el éxito-escándalo de La brecha haya sido solo por eso. Por el contrario, me parece que la novela, efectivamente, responde a las inquietudes de las mujeres de su generación y les ofrece una respuesta exitosa a un problema común: el cambio en los roles de género de las mujeres de los años sesenta en un contexto emancipatorio. A diferencia del cuento de Bombal, que no asume asuntos prácticos como el dinero y el trabajo, la narradora de Valdivieso sí señala cómo vende sus joyas para poder mantenerse los primeros días (la protagonista es burguesa, muchas no viviríamos ni un día con ese capital) y, así mismo, cómo se incorpora al mundo laboral y qué implicancias tiene esto en su visión del mundo. Es, por ello, una suerte de "pedagogía feminista" que de manera denotativa "enseña" a emanciparse a las mujeres de clase media alta chilena y señalar vías de realización que no pasan por el matrimonio y los hijos.

Sintetizando, habría al menos tres momentos en la recepción crítica de $L a$ brecha de Mercedes Valdivieso. Al momento de ser publicada fue leída como un "escándalo" que se alimentaba por el desdibujamiento entre los géneros textuales: ¿era una novela o un testimonio? Si era un testimonio, ¿se podía tolerar lo testimoniado? Si era una novela, ¿cuál era su calidad literaria toda vez que se elegía voluntariamente el "tono mayor"? Luego, a finales de los ochenta y los noventa, de la mano de Lucía Guerra Cunningham, fue leída como la primera novela feminista de Latinoamérica. Tal como han señalado Lucía Guerra Cuninnigham, Marcelo Coddou y la misma Mercedes Valdivieso en diversas entrevistas, no sería el comportamiento sexual de la protagonista el que más ofendiera a estos primeros críticos, sino que el verosímil de mujer propuesto: el de una divorciada que triunfa. Este verosímil iría en contra de una gruesa tradición cultural en la que infieles y fugadas tienen como destino 
común el cementerio (Aizemberg 440). La brecha sería algo así como una hija de Juliete: bella, inteligente y exitosa y que lucra con su sexualidad solo cuando está casada, pues soltera, la disfruta. Las hijas de Justine, que se conforman con bordar y sufrir una pena de amor ante una tapicería inconclusa, no estarían totalmente convencidas del final feliz del amor romántico que es el matrimonio, ni siquiera o, sobre todo, las protagonistas de los cuentos bombalianos. Desde la teoría queer de los afectos -como la propuesta por Sara Ahmed-, La brecha puede leerse como una novela que desde lo literario desgarra, como su título sugiere, los conceptos de realización y felicidad basados en las normas heteropatriarcales respecto a la familia y el trabajo. En contra del sentido común de su época, que veía el trabajo asalariado como una fuente de realización personal al poder salir del oclusivo trabajo doméstico, en La brecha, siguiendo la tradición de Marta Brunet -pienso en "Soledad de la sangre" y en María Nadie-, no hay ninguna redención ni para el trabajo doméstico ni para el asalariado.

Aun con estilos literarios radicalmente distintos, tanto "El árbol" como $L a$ brecha desestiman los finales felices para las chicas jóvenes de la burguesía de aquella época. "Casarse bien", es decir, con un marido rico, tener hijos $\mathrm{y}$ vivir juntos y felices para siempre es reemplazado por viajes, locuras y amor, en el caso de "El árbol", y por la posibilidad de liberarse, incluso de la obligación de ser feliz o de "hacer feliz" a otros, en el caso de La brecha. La felicidad estaría, simplemente, afincada en la "libertad de ser" aun cuando esto significara que la de los demás quedara al otro lado de un árbol caído, tras la brecha (Ahmed 249).

Si en Bombal se alienta a dejar al marido viejo que da la espalda para dormir, la protagonista sin nombre de La brecha nos dice cómo hacerlo con todos los detalles prácticos, al punto de que casi podría leerse como una pedagogía feminista que establece un modo para dejar la casa marital con total éxito. Desde este punto de vista puede entenderse su lenguaje denotativo que dice pan al pan y vino al vino, pues la narradora elige, conscientemente, ser comprendida por las otras, ser una más de ellas y que estas puedan identificarse fácilmente con la protagonista y tomar, entonces, valor.

Gracias a la mezcla de géneros (novela y testimonio), se logra desautomatizar la percepción de "lo ficticio" y "lo real", para así proponer un nuevo verosímil social de la mujer. "El personaje de esta novela no tiene nombre, pero podría ser el de cualquier mujer de nuestra generación" (Valdivieso 8) produce un efecto que equipara a la autora con la narradora, y a esta con el colectivo "mujeres de la generación del sesenta". El anónimo las cobija 
a todas. Si bien es cierto que uno de los tópicos de la narrativa femenina chilena es la protesta -explícita o implícita- contra los relatos religiosos, morales, literarios, legislativos, políticos, etcétera, que actúan en contra de una expansión personal y social de las mujeres - pienso en Shade, Iris, Teresa Wilms, Marta Vergara e incluso en María Luisa Bombal-, solo en Valdivieso existe la intención de universalizar este problema. La brecha aspira a la identificación con "cualquier mujer". El texto postula que es la sociedad entera la que está en crisis. Existe una pérdida de la fe en instituciones que hasta hace poco tiempo normaban el comportamiento social y vida privada de las personas. La protagonista comprueba que el matrimonio no es "para siempre", que el trabajo no "dignifica al hombre" (ni a las mujeres) y que la religión es "el opio del pueblo". La brecha señala una ruptura entre distintos roles de género (madre-esposa y mujer que trabaja); entre la posición de dependencia económica y la de mujer que se sustenta a sí misma; entre la familia de formato clásico (madre, padre, hijo) y una que excluye al padre e incorpora a la abuela materna y a los amigos en la crianza. Pero, sobre todo, es una ruptura con lo que se espera que haga, sea y diga una mujer burguesa, chilena, de aquella época. La ruptura matrimonial y la consecuente entrada al mundo laboral profundizan el conflicto. Pues tanto el espacio público como el privado estarían cruzados por el mismo sistema de poder patriarcal. Acá no solo es el feminismo el que sustenta la ideología en la novela sino también un diálogo con el marxismo, que sirve para explicar el por qué en la "sociedad capitalista" el trabajo se constituye en una "maldición" y cómo este podría dejar de serlo. Para el joven Marx de los Manuscritos económico-filosóficos (1844), el trabajo sería lo que nos constituye en humanos, del mismo modo que el trabajo alienado sería la causa de nuestra desintegración. El tipo de matrimonio que conoció la generación anterior a la de Mercedes Valdivieso correspondía a una estricta división de espacios y trabajos. El no tener acceso al espacio público, al trabajo ni al dinero, convierte al matrimonio en una forma de ganarse la vida: estar casadas se vuelve una "profesión" que, aunque sin salario garantiza, al menos casa y comida para el empleado. Para muchas, el contrato matrimonial tenía que ver más con el temor a la pobreza o al estigma de la solterona que con el amor. Por lo tanto, el trabajo remunerado se constituye en una alternativa a la del matrimonio:

$-\mathrm{Y}$ creo que es falta de firmeza contigo. Voy a tenerla. Debes pensar que al menos quien paga y mantiene tus gastos soy yo; aunque sea solo por eso me respetarás 
-Si se trata de compensaciones en dinero..., puedo trabajar.

-Jamás aceptaré que lo hagas, no digas tonterías (Valdivieso 42).

La brecha registra el desencanto producido al ver que el afuera no es la tierra prometida. Y que el trabajo, más que una forma de liberación y de autorrealización, es una forma de sometimiento. En el texto se postula que la fuerza ejercida como violencia y la dependencia económica son los mecanismos más frecuentes para mantener a las mujeres bajo control masculino:

-Juntos estamos mal, salvémonos como podamos.

-¿Qué estás proponiendo?

-Vencí el miedo

-Estoy hablando de separarnos

- ¿Abandonarme, quedarte suelta, irte con el niño?

-Lo que pienso es trabajar, mantener mi hijo, vivir en paz.

- ¿Supones que yo aceptaré haber fracasado en mi matrimonio?

Seguiremos juntos aunque sea necesario darte de bofetadas (Valdivieso 54).

En este sentido, el trabajo asalariado es una herramienta para poder tomar mínimas decisiones y obtener algún grado de independencia personal: "el dinero ganado me alejaba, segura económicamente, ¿cómo podría cogerme? Ya no estaba en vigencia aquello del respeto debido a quien lleva y mantiene los gastos, su última arma descargada contra mí” (Valdivieso 123). Sin embargo, las aspiraciones de autorrealización e independencia se esfuman cuando se ingresa al mundo del trabajo. La satisfacción de saberse autosustentada se diluye ante la poca relación que hay entre ella y lo que hace:

-Eres una respetable mujer, trabajas, sostienes tu hogar.

-¡Dios! QQué otra cosa me queda!

- ¿Te gusta lo que haces?

-Nadie acá me lo ha preguntado. Lo recibí como una orden desde arriba y eliminaron así toda posibilidad de elección verdadera (Valdivieso 132).

En su paso por la oficina, la protagonista narradora nos muestra cómo para ella y para el resto de sus compañeros el trabajo no posee ninguna dimensión épica, religiosa ni solidaria: "Desde la maldición de Dios golpeaba 
el imperativo: ¡Trabaja! Para la mayoría sin sentido, sin entusiasmo, por deber, no por conciencia de futuro: trabaja" (Valdivieso 128).

Así, la protagonista nos muestra que el trabajo está pervertido, que no sirve para crear ni expresarse, sino, por el contrario, para reproducir un sistema opresivo:

Recorría las oficinas y observaba a los muchachos inclinados en sus escritorios, totalmente sometidos. La canalización de sus vidas era tan definitiva, que apartarlos de la obediencia y la obligación sería dejarlos botados. Se movían dentro del terrible molde que ha conformado sus cerebros (Valdivieso 233).

La narradora alude al Marx de los Manuscritos económico-filosóficos cuando se pregunta por un posible sentido en el acto de trabajar, que pase de ser una instancia de alienación a una posibilidad de realización": "¿Llegaría el día en que cada uno se realice en lo que le dé de comer? Humanizar el trabajo, liberándolo así de ser obligación, convirtiéndolo en posibilidad, dejar de ser reo en trabajos forzados" (ibid.).

$\mathrm{Al}$ igual que en "El árbol", cuya protagonista rememora en la sala de conciertos, la solución que se nos plantea en el texto se relaciona con el mundo del arte. Sin embargo, no se trata de un volver al refugio del cuarto de vestir, al mundo de las perpetuas formas en movimiento en el que los sentidos se recrean. Por el contrario, se trata de incorporar "las jaulas", las "rejas" y la "fealdad" que penetran este espacio artístico y privado de la protagonista de "El árbol". La brecha plantea el arte al servicio del pueblo como una solución al trabajo alienante:

Recordaba a un tío, hermano de mi madre, dibujante desde que aprendió a sostener el lápiz y que se negó a hacer otra cosa de su vida. Muy joven aún enfermó gravemente; se sentaba entonces frente a la ventana y dibujaba escenas callejeras, siempre había una niñita o un obrero posando en su estudio. Avisaron a mi madre cuando ya no pudo manejar sus manos; ella quiso llevarlo a un pensionado y él se negó terminantemente:

6 “ 'S $]$ u trabajo no es voluntario sino impuesto, es un trabajo forzado [...] Su carácter ajeno se demuestra claramente en el hecho de, tan pronto como no hay una obligación física o de otra especie es evitado como la plaga" (Marx 204). 
-He pintado al pueblo; con él quiero morir.

Jamás se refirió a sus dibujos como a un trabajo y lo había estado realizando hasta el fin. En él no se cumplió la maldición bíblica (Valdivieso 133).

"La denuncia de la sociedad moderna que está en crisis" ("Autora de $L a$ brecha"11) y la vinculación de La brecha con una generación que excede lo individual hacen pensar que el proyecto literario de la autora se entronca también con el marxismo. El pensamiento de izquierda es expresado en el discurso de una "recién conversa", que inicia el "catecismo" mencionando a la Iglesia como el "opio del pueblo", sigue con la alusión a la excomunión de los comunistas por parte del Papa (Valdivieso 102), y finaliza con la explotación económica, la "Mina vaciándose en inglés" (Valdivieso 121). Así, Valdivieso lleva esta discusión al seno de la vida privada y a las relaciones entre los personajes. La protagonista constata a través de su "aprendizaje" que ni en lo privado ni en lo público se es verdaderamente independiente, pues en ambos espacios debe "someterse":

Pongo más leños al fuego y pienso que soy como un recluso que hizo saltar la cerradura de su calabozo y a quien después de ciertas escaramuzas, le está permitido pasearse por la enorme cárcel, conversar con los presos en sus celdas y luego sentarse a esperar frente a la puerta. Porque es allí afuera donde está la libertad... (Valdivieso 142).

Desde un avión, la protagonista observa tanto lo privado como lo público que define como espacios cruzados por la lucha y la competencia patriarcal. Es entonces cuando decide ser escritora. Aún "en tono mayor sostenido", con dolor o libre de él, asume denunciar los costos y los riesgos de ser. Elegir la escritura la libera de ser esposa y trabajadora alienada. En ese grito, que cruza el cielo y la tierra, estaría el germen de su escritura; una nueva forma de reconfigurarse para ella y para las mujeres de su generación a quienes ofrenda su novela:

Hasta allí suspendidos en el espacio llegaban las emanaciones de la tierra desde todos los ángulos, el pensamiento saltaba de un punto a otro, todo de golpe en un primer plano... Allí está Camila preparándose para su primer matrimonio... tiene diecisiete años. Los niños, el mío, juegan a matar; las tiras cómicas se amontonan en sus veladores; en ellas el valor se aprueba liquidando al adversario, lo más rápidamente 
posible. El Papa excomulga a los marxistas, ¿Qué puede importarles si son ateos?... Por primera vez pensé en escribir un libro; sería como una catarsis, no contar nada: gritar, dejar los tonos menores, tono mayor sostenido (Valdivieso 102).

En una especie de limbo están los que la narradora describe como "la masa gris". Gente sin nombre y sin cara que deambula por la ciudad. La mirada de la narradora sobre ellos es compasiva y superficial: son los que no tienen dinero para taxi y que, por ende, viven como esclavos de los horarios, "los muchachos inclinados en sus escritorios, totalmente sometidos" (Valdivieso 133). La narradora no se reconoce en ellos: son verdaderamente "lo otro".

Gran parte de las novelas escritas por mujeres en Chile corresponde a mujeres burguesas que escriben sobre problemas que afectan a su clase y que se resuelven también desde los problemas y privilegios de ese lugar. Marta Brunet, y luego Diamela Eltit, recogen la tradición de la narrativa social chilena, pero le incorporan la épica de las mujeres. Son las "rucias", las "pericas lumpen", las "Coya-Coa" quienes, desde su resistencia, hablarán por todas las demás. En la narrativa de Eltit se reescriben tanto los aspectos transformadores del realismo de Droguett y de Donoso como el neocriollismo feminista de Brunet, al narrar desde la perspectiva de las percibidas como otras de las otras. No hay "dramas burgueses" en la narrativa de Eltit, tampoco en Brunet, sino la inequidad patriarcal que se combate y resiste.

Pasarán más de veinte años para que esos "otros" de la narrativa de Valdivieso mezclen sus luchas con la de las mujeres y marchen desde la plaza de Lumpérica (1983) hasta la Alameda de Sumar (2018). Al cerrar la última página, las novelas de Eltit se abren a la sociedad y al contexto no ficcional.

\section{CODA}

Este texto es una reescritura de un material inédito de mi tesis de magister en Literatura, "Bombal, Valdivieso, Eltit: Tejiendo una tradición" (1991), alojado en el archivo de Diamela Eltit en la Universidad de Princeton. Sesenta años después de La brecha y treinta años después de la escritura de estos materiales, veo materializarse el marxismo y el feminismo en las manifestantes del mayo feminista, que abogaron por el personal femenino no contratado en las universidades haciendo un vínculo interseccional, como adelantó Mercedes Valenzuela-Valdivieso y luego Diamela Eltit. 
Este 2021, en la primera sesión de la Convención Constituyente se escucha el "tono mayor sostenido" de Elsa Labraña, que exige que no se inicie la ceremonia mientras no pare la represión a los manifestantes que se agolparon a la salida del ex-Congreso Nacional. Asimismo, la voz llena de templanza de Carmen Gloria Valladares acuerda que así sea. Afuera está la clase que ha representado tímidamente Valdivieso y que se toma con propiedad las páginas de Eltit para pedir lo mismo que pide Valenzuela-Valdivieso: que paren las violencias, las de género y las sociales. Son las voces colectivas, las de todas, las que pueden ser finalmente escuchadas. Sin Elsa, Carmen Gloria no sabe ni tiene apoyo para detener en el momento justo la represión; sin Carmen Gloria, probablemente se hubiera hecho un acto democrático en un contexto abusivo e impune. Y no vale la pena, de verdad, discutir quién tiene el tono más o menos patriarcal, pues a la hora del guanaco patriarcal, donde a casi nadie escuchan, solo oirán las voces de todas. Por ello, observo el "final feliz" de la protagonista sin nombre de La brecha, que es la propia realización y publicación de la novela, como un camino posible para las mujeres que se quieren libres, creativas, pensadoras:

-¿Cómo quisiera ser reconocida por la posteridad?

-Como una representante del momento que le tocó vivir, y cuyos conflictos se atrevió a retratar desafiando el escándalo y el rechazo que esto pudiera significar. Me gustaría dejar una referencia al futuro sobre esta sociedad y nuestra época: "libre, feliz y realizada" ("Autora de La brecha" 11).

\section{BIBLIOGRAFÍA}

Aizemberg, Edna. "El 'Bildungsroman' fracasado en Latinoamérica: el caso de 'Ifigenia' de Teresa de la Parra”. Revista Iberoamericana 51, №132, 1985, pp. 539-546. Agosín, MARJoRIE. Las desterradas del reino: protagonistas en la narrativa de María Luisa Bombal. Nueva York, Senda Nueva de Ediciones, 1983.

Ahmed, SARA. "Feminista aguafiestas" La promesa de la felicidad, una crítica cultural al imperativo de la alegría. Buenos Aires: Caja Negra, 2019, pp. 123-193.

Alegría, Fernando. Literatura chilena del siglo XX. Santiago, Zig-Zag, 1962.

“Autora de La brecha: No soy la protagonista”. Ercilla, 1933, p. 11.

Berenguer, Carmen, Eugenia Brito, Diamela Eltit, Raquel Olea, Eliana Ortega y 
Nelly Richard (comp.). Escribir en los bordes. Congreso Internacional de Literatura Femenina

Latinoamericana. Santiago, Editorial Cuarto Propio, 1990.

Bombal, María Luisa. La amortajada y El árbol. Zig-Zag, 1984.

Brunet, Marta. "Soledad de la sangre”. Aguas abajo. Santiago, Nascimiento, 1943.

María Nadie. Santiago, Pehuén, 1977. Amasijo. Santiago, Zig-Zag, 1962.

Cumes, Aura. "Mujeres indígenas, patriarcado y colonialismo: un desafío a la segregación comprensiva de las formas de dominio". Anuario Hojas de Warmi 17, 2012, pp. 1-16.

Coddou, Marcelo. "Relectura de La brecha. Veinte estudios sobre literatura chilena",

Inti: Revista de literatura hispánica 1, º29, 1989, pp. 39-48.

Eltit, Diamela. Por la patria. Santiago, Ediciones del Ornitorrinco, 1986.

Mano de obra. Santiago, Planeta, 2001.

Sumar. Santiago, Planeta, 2018.

Figueroa, Carmen. "Escritora de espacios", El Mercurio, 28 marzo 1989, p. 6.

Guerra Cunningham, Lucía. "Feminismo y subversión en La brecha de Mercedes

Valdivieso". Texto e ideología en la narrativa chilena. Lucía Guerra Cunningham, Institute of Ideologies and Literatures, 1987.

Hernández, Elvira. "Desclasificación”. Los trabajos y los días. Elvira Hernández,

Santiago, Lumen, 2016, p. 183.

Larraín, Ana María. "Mercedes Valdivieso: la extravagancia es el precio de mi libertad",

El Mercurio, 1991.

"Los carteles que se robaron las miradas en la histórica marcha del \#8M en Chile", T13 (web),

9 de marzo de 2019, consultado el 21 de noviembre de 2021, disponible en: https://www.

t13.cl/noticia/nacional/Los-carteles-que-se-robaron-las-miradas-en-la-historica-marchadel-8M-en-Chile

MarX, Karl. Manuscritos económico-filosóficos. Ciudad de México, Fondo de Cultura

Económica, 1983.

Milton, John. Paraíso Perdido. Buenos Aires, Orión, 1978.

Olea, Raquel. "Escritoras de la generación del cincuenta: claves para una lectura

política". Universum 25, N², 2010, pp. 101-116.

Owens, Craig. "El discurso de los otros: las feministas y el posmodernismo". $L a$ posmodernidad. Hal Foster (comp.), Barcelona, Kairós, 2002, pp. 93-124.

"Proceso a la Morbosidad". Diario Ilustrado, septiembre de 1961 (s/p Archivo Pedro Lastra Biblioteca Nacional).

Rojas, Manuel. Historia breve de la literatura chilena. Santiago, Zig-Zag, 1964.

Silva Castro, Raúl. "En el campo de la novela femenina". La Nación, 10 de noviembre de 1965. 
TAPIA, GloRIA. "Diputados Urruticoechea y Jürgensen pidieron a UCH y Usach rendir cuenta sobre programas relacionados con ideología de género y recursos invertidos", Radio Agricultura (web), 21 de octubre de 2021, consultado el 15 de noviembre de 2021, disponible en: https://www.radioagricultura.cl/politica/2021/10/21/diputados-urruticoechea$\mathrm{y}$-jurgensen-pidieron-a-uch-y-usach-rendir-cuenta-sobre-programas-relacionados-conideologia-de-genero-y-recursos-invertidos.html

Torres DujISIN, IsABel. "La década de los sesenta en chile: la utopía como proyecto". HAOL 19, 2009, pp. 139-149.

VALDÉS, ADRIANA. "Novelistas chilenas (Breve visión histórica y reseña crítica)". Aisthesis 3, 1968, pp. 113-130.

VAldivieso, Mercedes. La brecha. Santiago, Zig-Zag, 1961. 